\title{
The Longitudinal Impact of a Chronic Physical Health Condition on
}

\section{Subjective Well-being}

Caroline Debnar ${ }^{1,2,3}$, Valerie Carrard ${ }^{1,2,3}$, Davide Morselli ${ }^{3}$, Gisela Michel $^{2}$, Nicole Bachmann ${ }^{4}$, Claudio Peter ${ }^{1,2,3}$

${ }^{1}$ Swiss Paraplegic Research (SPF), Nottwil, Switzerland

${ }^{2}$ Department of Health Sciences and Medicine, University of Lucerne

${ }^{3}$ Swiss Centre of Expertise in Life Course Research LIVES, University of Lausanne

${ }^{4}$ University of Applied Sciences and Arts Northwestern Switzerland

\begin{abstract}
Author Note
Caroline Debnar (iD https://orcid.org/0000-0003-2346-621X

Valerie Carrard (iD https://orcid.org/0000-0001-7355-9567

Davide Morselli (iD https://orcid.org/0000-0002-1490-9691

Gisela Michel (iD https://orcid.org/0000-0002-9589-0928

Nicole Bachmann (D) https://orcid.org/0000-0001-8760-9027

Claudio Peter (iD https://orcid.org/0000-0001-9713-3210
\end{abstract}

The authors have no conflict of interest to disclose.

This project was funded by the Swiss Centre of Expertise in Life Course Research LIVES, which is financed by the Swiss National Science Foundation [grant number 51NF40 - 185901]. This study also uses the data collected by the Swiss Household Panel (SHP), which is based at the Swiss Centre of Expertise in the Social Sciences FORS.

Correspondence concerning this article should be addressed to Caroline Debnar, Swiss Paraplegic Research, Guido A. Zäch-Strasse 4, CH-6207 Nottwil, Switzerland. E-mail: caroline.debnar@paraplegie.ch 


\section{Abstract}

Objective: Chronic health conditions (CHC) can have severe impacts on an individual's life, affecting well-being and mental health. Nonetheless, individuals can show different response patterns of psychological adaptation following a CHC onset. This study aimed to identify profiles of subjective well-being (SWB) at one year before (T-1), one year after $(\mathrm{T}+1)$, and four years after $(\mathrm{T}+4)$ the onset of a physical CHC using seven indicators (health satisfaction, life satisfaction, energy, joy, worry, sadness, anger), examine transitions between the identified profiles, and determine predicting factors of these transitions. Method: Latent profile analysis and latent transition analysis was conducted using a sample of 357 participants reporting a physical CHC drawn from the Swiss Household Panel dataset. Results: Three profiles were identified at T-1: low, high, and very high SWB. At $\mathrm{T}+1$ and $\mathrm{T}+4$, a fourth vulnerable profile emerged. Transition analysis showed that, overall, the most probable transition was to stay in similar profiles across time. However, recovery towards higher SWB profiles and delayed reaction towards lower SWB profiles appeared between one and four years following the $\mathrm{CHC}$ onset. Factors predicting recovery patterns from low to high SWB are better health status, fewer negative life events, and financial scarcity, whereas lower emotional stability was related to a delayed reaction from high to low SWB.

Conclusion: This study underlines the importance of personal factors in the adaptation following CHC onset. Routine assessment of personality traits would enable to identify individuals at greater risk of lower SWB following the onset of a CHC.

Keywords: personality, chronic disease, psychological adaptation, subjective well-being, latent transition analysis. 


\section{The Longitudinal Impact of a Chronic Physical Health Condition on}

\section{Subjective Well-being}

The steadily rising prevalence of chronic physical health conditions $(\mathrm{CHC})$ is linked to several risk factors such as disadvantageous health behaviors, environmental pollution, and an increasingly aging population (IHME, 2018). Physical CHCs are defined as health problems persisting for a prolonged period - such as arthritis, cardiovascular diseases, cancer, and diabetes (WHO, 2019). The onset of a physical CHC can go hand in hand with psychological comorbidities, and people have to psychologically adapt to their health condition (Livneh, 2001). Psychological adaptation refers to the multidimensional and temporal process fostering mental and emotional balance in response to adversity, such as the onset of a CHC. Psychological adaptation models, such as the Psychosocial Adaptation to Chronic Illness and Disability model (Livneh, 2001), assume that the onset of a CHC will have differential impact on psychological outcomes such as life satisfaction, mental health, or other indicators of well-being. Even though each physical CHC has distinct symptomology, affected individuals are often faced with similar strains, such as long-term engagement, self-management, or impacts on well-being (Scharn et al., 2019). Thus, it has been proposed that studying psychological adaptation in a sample across different types of physical CHC would enable drawing more general conclusions on the impact of CHCs on mental health (Van Leeuwen et al., 2012). Nevertheless, so far, studies focused exclusively on one single type of CHC.

Historically, psychological adaptation has been first studied in terms of post-traumatic stress disorder or other psychiatric symptoms. However, the presence of negative symptoms does not necessarily imply an absence of positive affect or negative evaluation of one's life and vice versa. For example, research focusing on bereavement has shown that individuals may have a negative evaluation of their own life or experience low positive affectivity without displaying increased levels of distress. Consequently, the study of psychological adaptation needs a multidimensional assessment across a range of positive and negative indicators (Infurna \& Luthar, 2018). A 
multidimensional way of empirically defining psychological adaptation outcomes is subjective well-being (SWB). Diener's tripartite SWB model includes a positive cognitive evaluation of life overall (i.e., global life satisfaction) or specific life domains (e.g., health satisfaction), the presence of positive affect (e.g., feelings of joy), and the absence of negative affect (e.g., feelings of sadness; Diener, 1984). Studies using multidimensional indicators of psychological adaptation following physical CHC identified different patterns of mental health or well-being following myocardial infarction (Martens et al., 2007), rheumatoid arthritis (Morris et al., 2011), or spinal cord injury (Aparicio et al., 2020). These studies used cluster or profile analyses to identify subgroups of individuals sharing similar patterns across different indicators. Their results indicate three to four different patterns of psychological adaptation, such as "Non-depressed” (Morris et al., 2011), "low positive affect" (Martens et al., 2007), or "minimal impact" (Aparicio et al., 2020). Nevertheless, these profile studies are limited by their cross-sectional design.

In this regard, another important aspect of psychological adaptation is its temporality. Psychological adaptation is a more or less long-lasting process unfolding through several years (Galatzer-Levy et al., 2018). Past studies investigating longitudinal trajectories shed light on heterogeneous patterns, such as recovery or delayed reaction, to the $\mathrm{CHC}$ onset that could not be detected with cross-sectional design (Debnar et al., 2020; Galatzer-Levy et al., 2018). Latent transition analysis (LTA) is a statistical technique that enables, not only to identify patterns or profiles of response across multiple indicators of psychological adaptation but also their longitudinal unfolding. After identifying profiles of psychological adaptation at several time points, LTA enables determining the probability of each individual staying in the same profile or change to any other profile from one-time point to the other. For instance, a study on spousal bereavement by (Bennett et al., 2019) identified three psychological adaptation profiles - vulnerable (7\%), coper (39\%), and resilient (54\%) - across five well-being measures: depression, hopelessness, loneliness, life satisfaction, and subjective health. The results of an LTA then showed that most of the individuals stayed in the same profile across the two years following bereavement, with few 
participants changing to another profile. The use of LTA has thus the potential to shed light on the heterogeneity of the psychological adaptation process as well as its temporal unfolding and predicting factors.

Several theoretical models, including the spinal cord injury adjustment model (Middleton \& Craig, 2008), the model of psychosocial adaptation to chronic illness and disability (Livneh, 2001), or the coping with chronic disease model (Maes et al., 1996), conceptualize the predicting factors influencing the psychological adaptation following the onset of a $\mathrm{CHC}$. These factors include biological (e.g., health status), psychological (e.g., personality), social (e.g., social support), or sociodemographic (e.g., age) aspects. Empirical studies have shown that factors associated with better mental health or well-being following the onset of a physical $\mathrm{CHC}$ are: better health such as overall better health status (Burton et al., 2015), or better self-rated health (Zhu et al., 2014), higher emotional stability, openness, extraversion, conscientiousness (Hampson \& Friedman, 2008; Strickhouser et al., 2017), more social support (Debnar et al., 2020; Li et al., 2018), and more spirituality (Harris et al., 2010). On the other hand, factors such as income (Lyons et al., 2016), past negative life events (Butler et al., 1999), civil status (Havik, 1990; Moergeli et al., 2012), education (Morris et al., 2011; Van Leeuwen et al., 2012), sex (Moergeli et al., 2012; Zhu et al., 2014), and age (Havik, 1990; Moergeli et al., 2012) have been inconsistently associated with psychological adaptation following a physical CHC.

The objective of the present study was to describe the multidimensional and longitudinal process of psychological adaptation following different types of physical $\mathrm{CHC}$ with the inclusion of pre-event data in a non-clinical population. The first aim was to identify the number and type of psychological adaptation profiles one year before, one year after, and four years after the onset of a physical non-congenital CHC. Studies exploring psychological adaption identified three to four heterogeneous profiles with varying levels of mental health or well-being following the onset of a CHC (Aparicio et al., 2020; Martens et al., 2007; Morris et al., 2011). For instance, (Martens et al., 2007) reported three profiles of SWB following myocardial infarction. Including one profile 
characterized by the absence of negative affect and the presence of positive affect, a second profile characterized by low positive affect and absence of negative affect, and the third characterized by a relative absence of positive affect and the presence of negative affect. Based on the research conducted in other countries, it was expected to identify three to four profiles with varying psychological impact levels. The second aim was to explore the probability of transition between the profiles identified in each of the three time-points. In line with literature about trajectories following adversity, it was expected to identify three to five transition patterns, including a stable high, recovery, and stable low transition (Galatzer-Levy et al., 2018). Finally, the third aim of the study was to identify which health-related, psychological, social, and demographic factors predict the transition between one and four years after the onset of the CHC. Based on the literature reviewed above, it was hypothesized that better health (Burton et al., 2015; Zhu et al., 2014), higher emotional stability (Hampson \& Friedman, 2008; Strickhouser et al., 2017), more social support (Debnar et al., 2020; Li et al., 2018), higher sense of spirituality (Harris et al., 2010), and less financial scarcity (Lyons et al., 2016) would increase the probability of better psychological adaptation. Further, it was expected that profile transition is not predicted by age, sex, civil status, or education (Moergeli et al., 2012; Morris et al., 2011).

\section{Method}

\section{Study Design, Data Source and Sample}

This longitudinal study investigated the transition between SWB profiles at one year before ( $\mathrm{T}-1)$, one year after $(\mathrm{T}+1)$, and four years after $(\mathrm{T}+4)$ the onset of a physical CHC. A diagram of the model design is available online as supplementary materials (Figure S1). This is a secondary analysis of data drawn from the waves 2007-2015 of the Swiss Household Panel (SHP). The SHP is a nationally representative yearly panel study following a random sample of Swiss private households and their individuals aged 14 or older. Data has been collected annually since 1999 (Voorpostel et al., 2018 for further information concerning the study and its sampling procedures). 
Participants from the SHP 2013 wave who indicated the presence of a "chronic (long-standing) illness or condition (health problem)" self-reported as a "physical problem" and having started between 2009 and 2011 (T0) were considered for the present study. Exclusion criteria were congenital causes of the CHC. The exact items used to select the present study SHP sample are available online as supplementary materials (Table S2).

\section{Measures}

\section{SWB indicators}

Seven indicators of SWB, as defined by Diener (1984), were selected from the SHP dataset. They have been assessed at $\mathrm{T}-1, \mathrm{~T}+1$, and $\mathrm{T}+4$. Cognitive evaluation of life was measured with two items from the WHOQOL inventory (1998): health satisfaction ("How satisfied are you with your state of health, if 0 means "not at all satisfied" and 10 "completely satisfied?") and life satisfaction ("In general, how satisfied are you with your life if 0 means "not at all satisfied" and 10 means "completely satisfied"?"). The presence of positive affect was measured with two items: frequency of energy (“Are you often plenty of strength, energy, and optimism, if 0 means "never" and 10 "always"?") meant to measure the vitality subscale of the SF-36 inventory (Ware, 1999) and joy ("How frequently do you generally experience joy, if 0 means "never" and 10 "always"?”). The absence of negative affect was measured with the frequency of each of the following three negative emotions: worry, sadness, and anger ("How frequently do you generally experience the following emotion, if 0 means "never" and 10 "always"?"). The items joy, worry, sadness, and anger were selected to measure the so-called basic emotions (Ekman, 1992; Shaver et al., 1987).

\section{Predicting factors}

Health-related factors. In order to capture the influence of the CHC's symptoms three health-related factors were measured one year after the onset $(\mathrm{T}+1)$ : health status ("We are now going to talk about various aspects of your health: how do you feel right now?"; 1 = "very well"; 5 = "not well at all"), health impediment ("Please tell me to what extent, generally, your health is an 
impediment in your everyday activities, in your housework, your work or leisure activities? 0 means "not at all" and 10 "a great deal."), and improvement in health ("Since last year, has your health improved or worsened if 0 means "greatly worsened" and 10 "greatly improved"?").

Psychological factors. Personality was measured at the onset year (T0) with the 10-item Big Five Inventory (Rammstedt \& John, 2007). Participants indicated to what extent they see themselves as someone who, for instance, "is outgoing, sociable," "is reserved," "does a thorough job," or "has artistic interests" $(0=$ "completely disagree"; $10=$ "completely agree "). This validated questionnaire assesses five personality traits, with two items each: extraversion, emotional stability, conscientiousness, agreeableness, and openness. Given the low alpha of some personality trait, probably due to the low number of items, it was decided to only consider emotional stability and extraversion (Cronbach`s alpha $>.40$ see Table 1) for the present study. Spirituality was assessed two years before onset (T-2) with an indicator of participants' praying habits ("How frequently do you pray apart from at church or within a religious community?"; $1=$ "never" to $5=$ "daily or almost daily"). The number of past negative life event was measured by summing the number of time the participants indicated having experienced one of the following adverse life events between 2007 and 2015 (T-2 and T+4): “illness, accident of closely related person”, "death of closely related person", "termination of close relationship", "dismissal, unemployment", "financial difficulties", "material damage", and "psychological trauma".

Social factors. Relationship satisfaction and social contacts were assessed one year before onset (T-1). Relationship satisfaction was measured with the single variable: "How satisfied are you with your personal, social, and family relationships, if 0 means "not at all satisfied" and 10 “completely satisfied"?"). Social contact is an aggregation of the number ("With how many [...] are you on good terms and enjoy a close relationship?") and the frequency of contacts ("How frequent are your contacts with them?”) with close friends, relatives, neighbors, and colleagues separately.

Sociodemographic factors. Five sociodemographic characteristics assessed one year before onset (T-1) were included: partnership status (having a partner or not), education (years of 
education based on International Standard Classification of Education; Schneider, 2013), occupation (paid work or not), financial scarcity ("If you consider the total of your household's income and expenses, would you say that currently your household: $1=$ can save money; $2=$ spends what it earns; 3 = eats into its assets and savings; 4 = gets into debt?”), sex (man or woman), and age.

\section{Analysis}

In order to identify SWB profiles at $\mathrm{T}-1, \mathrm{~T}+1$, and $\mathrm{T}+4$, exploratory latent profile analysis (LPA) across the seven SWB indicators were performed for each time point. LPA is a personcentered approach that identifies subgroups of individuals with similar responses on a set of variables. In contrast to commonly used variable-centered cluster analyses such as factor analyses, LPA accounts for classification error and uncertainty, leading to a more precise estimation of the class membership. A more detailed description of applications and recent developments in LPA was published elsewhere (Collins \& Lanza, 2009). For T-1, two to five profiles were iteratively tested via maximum likelihood estimation with robust standard error. The best-fitting number of profiles was identified by comparing goodness of fit indices: the Bayesian Information Criterion (BIC; smaller number is preferable), the Bootstrap Likelihood Ratio Test (BLRT; non-significance indicates that the model with one less profile is better), entropy (high values $>.80$ indicate a high certainty of classification; Nylund, 2007), sample size per profile (profile sample size $>5 \%$ of the overall sample size), and interpretability of the profile parameters (based on past literature and theoretical meaningfulness). The best fitting profiles of T-1 were then considered as the baseline profiles and held constant (by fixing their indicators' means) in the analyses of the two other time points $(\mathrm{T}+1$ and $\mathrm{T}+4)$. This common procedure ensures that the profiles have the same configuration and the same interpretation across the three-time points and facilitates interpretation of transitions between profiles (Bennett et al., 2019). However, to enable the identification of heterogeneous profiles appearing after the onset of the $\mathrm{CHC}$, new freely estimated profiles were allowed to emerge at $\mathrm{T}+1$ and $\mathrm{T}+4$. For these post-event time points, an iterative process, starting 
from the fixed three baseline profiles, was applied to test increasing numbers of subgroup profiles until the best-fitting model was acquired using the same goodness of fit indices as for T-1.

The transition between the profiles identified at each of the three-time points was then tested using LTA. To reliably transfer the parameter estimates of the identified profiles, random start values of the LTA were set equal to the maximum likelihood estimates of the previously conducted LPAs. LTA computes the probability of staying in the same profile or move between one profile to another from one-time point to the next while accounting for misclassification errors (Nylund, 2007). These probabilities represent the likelihood of each individual presenting profile $X$ at a certain time point to present a profile $\mathrm{Y}$ at the following time point. They vary between 0 (no likelihood to go from profile $\mathrm{X}$ to profile $\mathrm{Y}$ ) and 1 (maximum certainty to go from profile $\mathrm{X}$ to profile Y). In the case of multiple profiles at each time point, these probabilities are not easy to grasp because they represent likelihood for each specific profile separately. Thus, for clarity's sake, the results will be presented in terms of number of individuals showing the specific transitions. A transition probability of .50 between profile $\mathrm{X}$ and $\mathrm{Y}$ will thus be translated into $\mathrm{N}=30$ if the number of individuals (based on estimated posterior probabilities) is $\mathrm{N}=60$ for profile $\mathrm{X}$. Transition probabilities were allowed to be freely estimated.

Finally, to test which predicting factor relates to the transition probabilities between $\mathrm{T}+1$ and $\mathrm{T}+4$ an ANOVA version of a manual 3-step approach was used. This approach estimates the LPA and LTA models, computes the misclassification error rate, and use ANOVAs to test mean differences of predicting factors between the different transition patterns directly in the LTA model while adjusting for misclassification errors. This procedure has the advantage of identifying unequal means across profile transition, is particularly suitable for small sample size profiles, and it appears to be more resistant to shifts in the latent profile membership from Step 1 to Step 3 (Nylund-Gibson et al., 2019; Nylund-Gibson et al., 2014). To ensure that model results did not depend on local maxima, every final model was rerun with at least twice the random starts (default used $=102$; maximum tested $=80080$ ). Incomplete data for the SWB indicators were estimated using full 
information maximum likelihood, and missing values in the predictor variables were imputed using multiple imputations at the mean level (20 imputed datasets). Analyses were performed with Mplus version 8 , and the analysis syntaxes are available online as supplementary material (Mplus syntax S3-S6).

\section{Results}

\section{Descriptive}

In total, 356 (204 women and $152 \mathrm{men}$ ) participants of the SHP, indicating the presence of a physical non-congenital CHC having started between 2009 and 2011, were included in the present study. One year before the onset participants mean age was 54 years $(\mathrm{SD}=18.04), 77.97 \%$ of the participants reported having a partner, and the average years of education was $13.24(\mathrm{SD}=$ 3.32). Further, descriptive statistics of the total sample are provided in Table 1. Due to nonparticipation in some waves, there was a variation in the sample size per time-point: $\mathrm{N}=276$ one year before, $\mathrm{N}=325$ one year after, and $\mathrm{N}=334$ four years after the $\mathrm{CHC}$ onset. Skewness and kurtosis coefficients indicated that the SWB indicators were non-normally distributed (range = $1.20-0.93$ and $2.64-8.73$ for skewness and kurtosis respectively). Robust maximum likelihood estimation was thus used to withstand the non-normal distribution of the data (Muthén \& Muthén, 2010). Correlations between the predictor variables are available online as supplementary materials (Table S6).

\section{Profiles of SWB}

At one year before the onset (T-1), the fit indices indicated that a 4-profile solution should be selected (see Table 2). However, the 4-profile solution showed a very similar BIC index compared to the 3-profile solution and did not add any new information (the added, fourth profile was very similar to another one). Consequently, the final solution adopted for T-1was a 3-profile model, including a very high, high, and low SWB profile (see Figure 1.A). The least frequent profile 
$(14.08 \%)$ was labeled "very high $S W B$ " because the individuals of this profile displayed outstanding high levels of satisfaction with health and life, positive affects, and an outstanding low level of negative affects. The high SWB profile was the one displayed by the majority of the T-1 sample (44.99\%). It was characterized by a high level of satisfaction with health and life satisfaction, positive affect, and moderate negative affect. The low $S W B$ profile $(40.93 \%)$ featured low satisfaction with health and life satisfaction, low positive affect, and elevated negative affect.

At one year after the onset $(\mathrm{T}+1)$, fit indices indicated that a 4-profile solution best represents the data (see Table 2). As displayed in Figure 1.B, a fourth vulnerable profile (8.52\%) emerged on top of the three baseline profiles: very high (8.39\%), high (37.42\%), and low SWB $(45.72 \%)$. The emerging vulnerable profile was characterized by the lowest level of satisfaction with health and life and the lowest level of positive affect among all profiles. However, the individuals of the vulnerable profile were not the ones displaying the highest level of negative emotions. They indeed reported lower levels of negative emotion compared to the low SWB profile. Contrary to T-1, where the majority of the sample belonged to the high SWB profile, the majority of the $\mathrm{T}+1$ sample displayed a low $S W B$, and the percentage of the very high $S W B$ profile was lower than at T-1 (14.08\% vs. $8.39 \%)$.

At four years after the onset $(\mathrm{T}+4)$ fit indices indicated that a similar 4-profile solution best represented the data (see Table 2) including the very high (4.40\%), high (41.83\%), and low SWB (45.45\%) profiles from the baseline and a fourth vulnerable (8.31\%) profile (see Figure 1.C). Similarly, to the $\mathrm{T}+1$, profiles, the individuals of the $\mathrm{T}+4$ vulnerable profile were the ones who displayed the lowest level of satisfaction with health and life and the lowest level of positive affect among all profiles, but not the highest level of negative emotions. The majority of the sample belonged to the low $S W B$ profile, and the proportion of the very high $S W B$ was even lower than at $\mathrm{T}+1$ (8.39\% vs. $4.40 \%)$. Another presentation of the SWB profiles with reversed scores of worry, sadness, and anger is available online as supplemental material (Figure S8). 


\section{Longitudinal Transition between Profiles of SWB}

Profile transition between SWB profiles across $\mathrm{T}-1, \mathrm{~T}+1$, and $\mathrm{T}+4$ is represented in Figure 2 . For clarity's sake, the transitions are described in terms of numbers of individuals, but transitions probabilities are available online as supplementary materials (Supplementary Table S7). Given the relatively small number of observations, some transition cells were empty (e.g., from vulnerable to very high profile). From one year before the onset $(\mathrm{T}-1)$ to one year after the onset $(\mathrm{T}+1)$, individuals were most likely to stay in the same profile or go to a lower SWB profile after the onset of a CHC. The individuals in the low SWB profile had a very high probability to also display a low $S W B$ profile one year after the onset $(\mathrm{N}=100)$. Similarly, the individuals who showed a high $S W B$ profile at $\mathrm{T}-1$ were very likely to also show a high $S W B$ profile at $\mathrm{T}+1(\mathrm{~N}=115)$. However, from the very high $S W B$ profile at $\mathrm{T}-1$, a downward transition to the high $S W B$ profile $(\mathrm{N}=14)$ was less likely to occur than staying in the same profile $(\mathrm{N}=20)$ after the onset. From one year after the onset $(\mathrm{T}+1)$ to four years after the onset $(\mathrm{T}+4)$, the individuals in the high and low $S W B$ profiles showed a very high probability of staying in a similar type of profile $(\mathrm{N}=104$ and $\mathrm{N}=124$ respectively). Furthermore, individuals from the vulnerable and the very high SWB profiles also showed a moderate probability of staying in a similar type of profile four years later $(\mathrm{N}=20$ and $\mathrm{N}$ $=17$, respectively). However, more variety in profile transitions was observed from $\mathrm{T}+1$ to $\mathrm{T}+4$. First, an upward change (recovery pattern) was likely to occur from the low $S W B$ profile at $\mathrm{T}+1$ transitioning to the high $S W B$ profile $(\mathrm{N}=26)$ at $\mathrm{T}+4$. Second, a downward change (delayed reaction pattern) was likely to occur from the high $S W B$ profile at $\mathrm{T}+1$ transitioning to the low $S W B$ profile $(\mathrm{N}=18)$ at $\mathrm{T}+4$.

\section{Predictors of Transition between $\mathrm{T}+1$ and $\mathrm{T}+4 \mathrm{SWB}$ Profiles}

As a reminder, factors included in the predictor analysis of the recovery and delayed reaction transitions were: health status, improvement in health, health impediment, extraversion, emotional stability, number of life events, praying, relationship satisfaction, social contact, years of 
education, having no partner, occupation, financial scarcity, sex, and age. Given the small sample size of certain transition patterns from one year after the onset to four years after the onset, predictors were tested only for the recovery (staying in the low SWB profile vs upward change towards high $S W B$ ) and the delayed reaction (staying in a high SWB profile vs downward change towards low $S W B$ ) transitions. Individuals experiencing a delayed reaction (from high to low $S W B$ ) reported significantly lower emotional stability $(M=5.67, S D=1.87)$ compared to the individuals staying in the high $S W B$ profile $(M=6.85, S D=1.75), M D=1.17, t=2.31, p=.021$ with a medium effect size (Hedges' $g=0.67)$.

Regarding the individuals showing a recovery pattern (from low to high $S W B$ ), they have significantly better health status $(M=3.30, S D=1.45)$ compared to the individuals staying in the low $S W B$ profile $(M=2.39, S D=0.79), M D=0.91, t=3.37, p=.001$ with a large effect size (Hedges' $g=0.96)$. They also experienced fewer negative life events $(M=4.20, S D=4.37)$ compared to the individuals staying in the low SWB profile $(M=6.37, S D=6.22), M D=2.17, t=$ $2.25, p=.024$ with a medium effect size (Hedges' $g=0.37$ ) and reported greater financial scarcity $(M=2.91, S D=5.39)$ compared to the individuals staying in the low SWB profile $(M=1.47, S D=$ $0.68), M D=1.43, t=5.62, p<.001$ with a medium effect size (Hedges' $g=0.61)$. Note that all other factors tested as predictor did not significantly relate to the recovery or delayed reaction transition.

\section{Discussion}

The purpose of the present study was to identify heterogeneous profiles of SWB at one year before $(\mathrm{T}-1)$, one year after $(\mathrm{T}+1)$, and four years after $(\mathrm{T}+4)$ the onset of a CHC, to explore the probability of transition between these identified profiles, and to investigate which health-related, psychological, social, and demographic factors predict these transitions. One year before the onset of a CHC three profiles of SWB were identified. Following the $\mathrm{CHC}$ onset, a fourth profile displaying more vulnerable levels of SWB emerged. Across time, the most probable transition was to stay in the same profile. However, between one and four years following the onset of $\mathrm{CHC}$, more 
heterogeneity in the transition patterns was observed. Better health status one year after the onset, fewer negative life events, and greater financial scarcity predicted recovery patterns from low to high $S W B$, whereas lower emotional stability was related to a delayed reaction form high to low $S W B$ between one and four years following a $\mathrm{CHC}$ onset.

\section{Profiles of SWB and Longitudinal Transition}

Analysis of pre-event data (T-1) show that before any CHC onset, people have different levels of SWB (very high, high, and low SWB) and present predominantly high SWB (44.98\%) with a smaller proportion displaying a very high $S W B$. The present study's results then show that the onset of a physical CHC increases the risk of lower SWB. Indeed, more than half $(54.97 \%)$ of the sample shows a low SWB or vulnerable profile at one year after the CHC onset. This percentage is higher than the one reported by past reviews of psychological adaptation following adversity (Galatzer-Levy et al., 2018). Thus, the present study is in line with several reports advocating that the proportion of individuals showing lower SWB after a negative life event has been underestimated in past studies (Infurna \& Luthar, 2016, 2018). Moreover, the identification of the vulnerable profile was only possible due to the use of multiple indicators. With a single indicator (e.g., joy), the identification of the vulnerable subgroup would not have been possible. Thus, the results of the profile analysis underlined the importance of a multidimensional perspective on psychological adaptation (Infurna \& Luthar, 2018).

The results of the transition analysis revealed a higher tendency for stability in profile membership rather than change. Indeed, across all time points, the most probable transition was to stay in the same profile over time. This is in line with other profile transition studies in the field of psychological adaptation following a bereavement or Parkinson's disease (Bennett et al., 2019; Landau et al., 2016) and suggests that previous levels of SWB influence the psychological adaptation process. However, the results revealed more variety in the transitions between one and four years following the onset of CHC. These transition pathways suggest the occurrence of recovery patterns (upwards transition to a profile with higher levels of SWB) and delayed reaction 
patterns (downwards transition to a profile with lower levels of SWB) in the aftermath of the CHC onset, which have also been observed in past studies analyzing longitudinal trajectories (GalatzerLevy et al., 2018).

Compared with the general population, individuals living with a physical $\mathrm{CHC}$ have a higher risk of sustaining lower mental health (Debnar, 2020). Similarly, the present study results demonstrate that half of the participants showed lower levels of SWB at least over three years. Moreover, the possibility of recovery or delayed reaction appears mostly between one and four years after the $\mathrm{CHC}$ onset. Together, the elevated risk of lower mental health and the observed transition interval underlines the need for long-term care of individuals sustaining a CHC. While a general practitioner follows up individuals suffering from diabetes or rheumatoid arthritis, other CHC's such as back pain or migraines do not necessarily imply systematic long-term care. The study results indicate that no matter the types of physical CHC, systematic follow-up appointments would be beneficial. Therefore, guidelines for the general practitioner should implement a systematic yearly follow-up for any CHC.

\section{Predictors of Longitudinal Transitions}

In the adverse life event literature, personality traits, such as emotional stability, have been shown to influence psychological adaptation (Hampson \& Friedman, 2008; Strickhouser et al., 2017). The results of the present study confirm that more emotional stability is a protective factor against a delayed reaction from high to low SWB between one and four years following the onset of a CHC. Thus, having information concerning the personality traits of $\mathrm{CHC}$ patients might help health professionals determining the individuals at greater risk of developing poor SWB. A study by Israel et al. (2014) demonstrated how integrating personality measurement into clinical practice might help to prevent poorer health outcomes. However, implementation research is needed to establish the cost, feasibility, and utility of integrating personality measurement into clinical practice. Moreover, studies suggested that personality traits can be changed (Lucas \& Donnellan, 2011; Roberts \& Mroczek, 2008). For instance, an intervention study showed that participants 
engaging in more cognitive-behavioral tasks such as journaling or practicing positive thinking increased their emotional stability scores from baseline to post-intervention (Hudson et al., 2018). In this sense, interventions tailored for individuals with lower emotional stability may be an avenue for the improvement of SWB following the onset of a CHC.

In line with previous studies, the results showed that better health (Burton et al., 2015; Zhu et al., 2014) and fewer past negative events (Seery \& Quinton, 2016) are associated with an improvement in SWB between one and four years following the onset of a CHC. A surprising finding was that more financial scarcity was related to a recovery pattern from low to high SWB. So far, longitudinal studies have shown that financial scarcity is related to lower mental health following CHC onset (Kariuki et al., 2011; Morin et al., 2017). The conflicting results of the present study might be due to the time measurement. Indeed, financial scarcity was measured one year before the onset and might not represent the individuals' financial situation after the onset of the CHC. Another explanation for this surprising finding is the socio-demographics of the sample. As one might expect in a CHC sample, the participants of the present study are quite old, and $30.31 \%$ are retired. When retirees report that their household eats into their assets and savings, it does not necessarily mean that they experience financial scarcity. In the Swiss context of the present study, the retirement pension is not sufficient to keep a lifestyle similar to the pre-retirement one (SousaPoza \& van Dam, 2001). Thus, retirees most often live from the savings accumulated before getting retired and it is nowadays considered as a normal financial situation during one's retirement.

The present study explored predicting factors across different types of physical CHC in an attempt to identify transversal factors that would predict psychological adaptation following any kind of CHC. Social support (Debnar et al., 2020; Li et al., 2018) or higher sense of spirituality (Harris et al., 2010) did not predict transition patterns of SWB in the present study. This unexpected finding may indicate that these factors may be protective factors in the case of specific types of $\mathrm{CHC}$, but not in the face of any type of $\mathrm{CHC}$. 


\section{Strength and Limitations}

The main strength of the present project lies in its prospective study design and state-of-theart statistical techniques, as well as its population based approach. Moreover, by using LTA, this study was able to shed light on the longitudinal unfolding of the psychological adaptation process while taking into account its multidimensionality. Besides, this study is one of the few using preevent data, which enables to identify the specific impact of the $\mathrm{CHC}$ onset.

Nevertheless, several limitations of the present project need to be acknowledged. First, a methodological limitation is that the SHP does not provide CHC diagnostic information. Thus, it was not possible to test whether presenting certain types of physical $\mathrm{CHC}$ would increase the risk of changing towards a lower SWB profile. However, studies including multiple health events have shown that the type of disease (i.e., heart disease, lung disease, cancer, and stroke) is not related to psychological adaptation (Debnar et al., 2020; Morin et al., 2017). Nevertheless, further studies are needed to confirm that common patterns of psychological adaptation can be observed following different types of CHC. Second, one should be aware that the degree of vulnerability is usually underestimated in general population datasets, such as the SHP because more physically impaired individuals participate less in cohort studies (Rothenbühler \& Voorpostel, 2016) and individuals living in institutions are typically excluded from such surveys (Voorpostel et al., 2018). Thus, the prevalence of vulnerable profiles in the present study might have been underestimated, and generalization to more physically impaired individuals should be done with caution. Third, the operationalization of psychological adaptation with measures that do not provide thresholds precludes any clinical assessment. Thus, the results of the present study do not inform on the potential risk of psychological disorders in the different profiles identified. Fourth, given that Switzerland is a developed country with a particular health system, including mandatory health insurance, the results could be comparable to developed countries having similar health services (mandatory health insurance or free health care) and similar age distribution. However, replication in other countries is needed to confirm the generalizability of the findings. Fifth, using secondary 
data limited the investigation of spirituality with only one item related to praying habits. Future investigation of multiple spirituality indicators would lead to a more multifaceted investigation of this complex concept. Sixth, performing multiple predictor analysis is known to increase type I errors, but a stricter p-value threshold using Bonferroni correction was not applied in the present study to avoid underpowered analysis and increased type II errors (Nakagawa, 2004). Hence, predictor findings need to be interpreted with caution, and further replications are advisable. Finally, the time spans between the psychological adaptation profiles are rather long (two to three years). Thus, short-time changes in SWB between the measurement time points cannot be observed. Future longitudinal studies would benefit greatly from incorporating more frequent assessment intervals to detect short-term fluctuations in SWB.

\section{Conclusion}

The 21 st-century health care systems face new challenges due to the aging population and the consequential increase in $\mathrm{CHC}$ prevalence. The present study investigated both the multidimensionality and longitudinal unfolding of psychological adaptation to the onset of a CHC. Despite a high degree of stability observed across time, this study points out the critical importance of long term care for individuals, because more varied transition patterns have been identified between one and four years following the onset of the CHC. In this sense, long-term care for individuals living with a physical CHC should be acknowledged, as it may be crucial to well-being improvement and prevention of potential comorbid depressive symptoms (Maurer et al., 2008). Personality traits and health status are factors predicting transitions between one and four years after the onset of a CHC. Integrating personality measurement might help health professionals determine which individual will be at greater risk for lower well-being. Furthermore, interventions increasing emotional stability is an avenue for better mental health of individuals living with a CHC. 


\section{References}

Aparicio, M., Carrard, V., Morselli, D., Post, M., Peter, C., Jordan, X., Léger, B., Baumberger, M., Gmünder, H., \& Curt, A. (2020). Profiles of psychological adaptation outcomes at discharge from spinal cord injury inpatient rehabilitation. Archives of Physical Medicine and Rehabilitation, 101(3), 401-411. https://doi.org/10.1016/j.apmr.2019.08.481

Bennett, K., Morselli, D., Spahni, S., \& Perrig-Chiello, P. (2019). Trajectories of resilience among widows: A latent transition model. Aging and Mental Health, 1-8. https://doi.org/10.1080/13607863.2019.1647129

Burton, C., Galatzer-Levy, I., \& Bonanno, G. (2015). Treatment type and demographic characteristics as predictors for cancer adjustment: Prospective trajectories of depressive symptoms in a population sample. Health Psychology, 34(6), 602-609. https://doi.org/10.1037/hea0000145

Butler, L., Koopman, C., Classen, C., \& Spiegel, D. (1999). Traumatic stress, life events, and emotional support in women with metastatic breast cancer: Cancer-related traumatic stress symptoms associated with past and current stressors. Health Psychology, 18(6), 555-560. https://doi.org/10.1037/0278-6133.18.6.555

Collins, L., \& Lanza, S. (2009). Latent class and latent transition analysis: With applications in the social, behavioral, and health sciences (Vol. 718). John Wiley \& Sons.

Debnar, C., Carrard, V., Morselli, D., Michel, G., Bachmann, N., \& Peter, C. (2020). Psychological distress trajectories in chronic physical health conditions. Health Psychology, 39(2), 116-126. https://doi.org/10.1037/hea0000820

Diener, E. (1984). Subjective well-being. Psychological bulletin, 95(3), 542-575.

Ekman, P. (1992). An Argument for Basic Emotions. Cognition and Emotion, 6(3-4), 169-200. 
Galatzer-Levy, I., Huang, S., \& Bonanno, G. (2018). Trajectories of resilience and dysfunction following potential trauma: A review and statistical evaluation. Clinical Psychology review, 63, 41-55. https://doi.org/10.1016/j.cpr.2018.05.008

Hampson, S., \& Friedman, H. (2008). Personality and Health: A lifespan perspective. In O. John \& L. Pervin (Eds.), Handbook of personality: Theory and research (pp. 770-794). The Guilford Press.

Harris, B., Berger, A., Mitchell, S., Steinberg, S., Baker, K., Handel, D., Bolle, J., Bush, E., Avila, D., \& Pavletic, S. (2010). Spiritual well-being in long-term survivors with chronic graft versus host disease after Hematopoietic Stem Cell Transplant (HSCT). The Journal of Supportive Oncology, 8(3), 119-125. https:/www.ncbi.nlm.nih.gov/pmc/articles/PMC3426915/

Havik, O. (1990). Patterns of emotional reactions after a myocardial infarction. Journal of Psychosomatic Research, 34(3), 271-285. https://doi.org/10.1016/0022-3999(90)90083-G

Hudson, N., Briley, D., Chopik, W., \& Derringer, J. (2018). You have to follow through: Attaining behavioral change goals predicts volitional personality change. Journal of Personality and Social Psychology, 117(4), 839-857. https://doi.org/10.1037/pspp0000221

IHME. (2018). Findings from the Global Burden of Disease Study 2017. Institute for Health Metrics and Evaluation (IHME). Retrieved 29.03.2019 from http://www.healthdata.org/policyreport/findings-global-burden-disease-study-2017

Infurna, F., \& Luthar, S. (2018). Re-evaluating the notion that resilience is commonplace: A review and distillation of directions for future research, practice, and policy. Clinical Psychology Review, 65, 43-56. https://doi.org/10.1016/j.cpr.2018.07.003

Infurna, F. J., \& Luthar, S. S. (2016). Resilience to major life stressors is not as common as thought. Perspectives on Psychological Science, 11, 175-194. http://dx.doi.org/10.1177/1745691615621271 
Israel, S., Moffitt, T., Belsky, D., Hancox, R., Poulton, R., Roberts, B., Thomson, W. M., \& Caspi, A. (2014). Translating personality psychology to help personalize preventive medicine for young adult patients. Journal of Personality and Social Psychology, 106(3), 484-498. https://doi.org/10.1037/a0035687

Kariuki, M., Honey, A., Emerson, E., \& Llewellyn, G. (2011). Mental health trajectories of young people after disability onset. Disability and Health Journal, 4(2), 91-101. https://doi.org/10.1016/j.dhjo.2010.08.001

Landau, S., Harris, V., Burn, D., \& Hindle, J. (2016). Anxiety and anxious-depression in Parkinson's disease over a 4-year period: A latent transition analysis. Psychological Medicine, 46(3), 657667. https://doi.org/10.1017/S0033291715002196

Li, X., Wang, B., Tan, D., Li, M., Zhang, D., Tang, C., Cai, X., Yan, Y., Zhang, S., \& Jin, B. (2018). Effectiveness of comprehensive social support interventions among elderly patients with tuberculosis in communities in China: A community-based trial. Epidemiol Community Health, 72(5), 369-375. https://doi.org/10.1136/jech-2017-209458

Livneh, H. (2001). Psychosocial adaptation to chronic illness and disability: A conceptual framework. Rehabilitation Counseling Bulletin, 44(3), 151-160.

https://doi.org/10.1177/003435520104400305

Lucas, R., \& Donnellan, M. (2011). Personality development across the life span: Longitudinal analyses with a national sample from Germany. Journal of Personality and Social Psychology, 101(4), 847. https://doi.org/10.1037/a0024298

Lyons, A., Heywood, W., \& Rozbroj, T. (2016). Psychosocial factors associated with resilience in a national community-based cohort of Australian gay men living with HIV. AIDS and Behavior, 20(8), 1658-1666. https://doi.org/10.1007/s10461-016-1338-5 
Maes, S., Leventhal, H., \& de Ridder, D. (1996). Coping with chronic diseases. In M. Zeidner \& N. Endler (Eds.), Handbook of coping: Theory, research, applications (pp. 221-251). John Wiley $\&$ Sons.

Martens, E., Smith, O., \& Denollet, J. (2007). Psychological symptom clusters, psychiatric comorbidity and poor self-reported health status following myocardial infarction. Annals of Behavioral Medicine, 34(1), 87-94. https://doi.org/10.1007/BF02879924

Maurer, J., Rebbapragada, V., Borson, S., Goldstein, R., Kunik, M., Yohannes, A., \& Hanania, N. (2008). Anxiety and depression in COPD: Current understanding, unanswered questions, and research needs. Chest, 134(4), 43-56. https://doi.org/10.1378/chest.08-0342

Middleton, J., \& Craig, A. (2008). Guide for health profes sionals on the psychosocial care of people with a spinal cord injury. In A. Craig \& K. N. Perry (Eds.), New South Wales: State Spinal Cord Injury Service.

Moergeli, H., Wittmann, L., \& Schnyder, U. (2012). Quality of life after traumatic injury: A latent trajectory modeling approach. Psychotherapy and Psychosomatics, 81(5), 305-311. https://doi.org/10.1159/000330887

Morin, R., Galatzer-Levy, I., Maccallum, F., \& Bonanno, G. (2017). Do multiple health events reduce resilience when compared with single events? Health Psychology, 36(8), 721-728. https://doi.org/10.1037/hea0000481

Morris, A., Yelin, E., Panopalis, P., Julian, L., \& Katz, P. (2011). Long-term patterns of depression and associations with health and function in a panel study of rheumatoid arthritis. Journal of Health Psychology, 16(4), 667-677. https://doi.org/10.1177/1359105310386635

Muthén, L., \& Muthén, B. (2010). Mplus User's Guide. Muthén \& Muthén.

Nakagawa, S. (2004). A farewell to Bonferroni: the problems of low statistical power and publication bias. Behavioral Ecology, 15(6), 1044-1045. https://doi.org/10.1093/beheco/arh107 
Nylund, K. (2007). Latent transition analysis: Modeling extensions and an application to peer victimization [(Unpublished doctoral dissertation), University of California]. Retrieved from http://www.statmodel.com/download/Nylund\%20dissertation\%20Updated1.pdf

Nylund-Gibson, K., Grimm, R., Quirk, M., \& Furlong, M. (2014). A latent transition mixture model using the three-step specification. Structural Equation Modeling: A Multidisciplinary Journal, 21(3), 439-454. https://doi.org/10.1080/10705511.2014.915375

Nylund-Gibson, K., Grimm, R., \& Masyn, K. (2019). Prediction from latent classes: A demonstration of different approaches to include distal outcomes in mixture models. Structural equation modeling: A multidisciplinary journal, 26(6), 967-985.

https://doi.org/10.1080/10705511.2019.1590146

Rammstedt, B., \& John, O. (2007). Measuring personality in one minute or less: A 10-item short version of the Big Five Inventory in English and German. Journal of Research in Personality, 41(1), 203-212. https://doi.org/10.1016/j.jrp.2006.02.001

Roberts, B., \& Mroczek, D. (2008). Personality Trait Change in Adulthood. Current directions in psychological science, 17(1), 31-35. https://doi.org/10.1111/j.1467-8721.2008.00543.x

Rothenbühler, M., \& Voorpostel, M. (2016). Attrition in the Swiss Household Panel: Are Vulnerable Groups more Affected than Others? In R. C. Oris M., Joye D., Ernst Stähli M. (Ed.), Surveying human vulnerabilities across the life course. Life Course Research and Social Policies (Vol. 3, pp. 221-242). Springer.

Scharn, M., Hengel, K., Boot, C., Burdorf, A., Schuring, M., van der Beek, A., \& Robroek, S. (2019). Influence of chronic diseases on societal participation in paid work, volunteering and informal caregiving in Europe: A 12-year follow-up study. Journal of Epidemiology and Community Health, 73(2), 136-141. https://doi.org/10.1136/jech-2018-211107

Schneider, S. (Ed.) (2013). The International Standard Classification of Education 2011 (Vol. 30). Emerald Group Publishing Limited. 
Seery, M., \& Quinton, W. (2016). Understanding resilience: From negative life events to everyday stressors. In J. Olson \& M. Zanna (Eds.), Advances in Experimental Social Psychology (Vol. 54, pp. 181-245). Elsevier.

Shaver, P., Schwartz, J., Kirson, D., \& O'connor, C. (1987). Emotion Knowledge: Further Exploration of a Prototype Approach. Journal of Personality and Social Psychology, 52(6), 1061-1086.

Strickhouser, J., Zell, E., \& Krizan, Z. (2017). Does personality predict health and well-being? A metasynthesis. Health Psychology, 36(8), 797-810. https://doi.org/10.1037/hea0000475

Van Leeuwen, C., Hoekstra, T., van Koppenhagen, C., de Groot, S., \& Post, M. (2012). Trajectories and predictors of the course of mental health after spinal cord injury. Archives of Physical Medicine and Rehabilitation, 93(12), 2170-2176. https://doi.org/10.1016/j.apmr.2012.07.006

Voorpostel, M., Tillmann, R., Lebert, F., Kuhn, U., Lipps, O., Ryser, V., Antal, E., Monsch, G., Dasoki, N., \& Wernli, B. (2018). Swiss Household Panel User Guide (1999-2017). FORS. Ware, J. (1999). SF-36 Health Survey. In M. E. Maruish (Ed.), The use of psychological testing for treatment planning and outcomes assessment (pp. 1227-1246). Lawrence Erlbaum Associates Publishers.

WHO. (2019). Integrated chronic disease prevention and control. World Health Organization.

Retrieved 15.04 from https://www.who.int/chp/about/integrated_cd/en/

WHOQOL Group. (1998). The World Health Organization quality of life assessment (WHOQOL):

Development and general psychometric properties. Social Science \& Medicine, 46(12), 15691585. https://doi.org/10.1016/S0277-9536(98)00009-4

Zhu, Z., Galatzer-Levy, I., \& Bonanno, G. (2014). Heterogeneous depression responses to chronic pain onset among middle-aged adults: A prospective study. Psychiatry Research, 217(1-2), 60-66. https://doi.org/10.1016/j.psychres.2014.03.004 
Table 1

Descriptive Statistics and Demographic characteristics

\begin{tabular}{|c|c|c|c|c|c|c|c|c|}
\hline & $M$ & $S D_{\mathrm{n}}$ & $\begin{array}{c}\% \\
\text { nissing }\end{array}$ & $\begin{array}{l}\text { Kurtos } \\
\text { is }\end{array}$ & $\begin{array}{r}\text { Skewn } \\
\text { ess }\end{array}$ & $\alpha$ & $\lambda$ & $\rho$ \\
\hline \multicolumn{9}{|l|}{ SWB indicators } \\
\hline Health Satisfaction T-1 & 7.61 & 1.56 & 30.80 & 3.65 & -0.68 & & & \\
\hline Health Satisfaction $\mathrm{T}+1$ & 6.92 & 1.84 & 11.42 & 4.81 & -1.04 & & & \\
\hline Health Satisfaction $T+4$ & 6.98 & 1.83 & 8.08 & 4.38 & -1.01 & & & \\
\hline Life satisfaction T-1 & 8.06 & 1.26 & 30.80 & 4.41 & -0.76 & & & \\
\hline Life satisfaction $\mathrm{T}+1$ & 7.74 & 1.37 & 11.11 & 5.98 & -1.20 & & & \\
\hline Life satisfaction $\mathrm{T}+4$ & 7.94 & 1.26 & 8.08 & 8.73 & -1.35 & & & \\
\hline Joy T-1 & 7.39 & 1.15 & 30.80 & 5.24 & -0.65 & & & \\
\hline Joy $\mathrm{T}+1$ & 7.38 & 1.35 & 11.42 & 4.86 & -0.64 & & & \\
\hline Joy $\mathrm{T}+4$ & 7.26 & 1.23 & 8.08 & 4.40 & -0.52 & & & \\
\hline Energy T-1 & 7.22 & 1.44 & 30.80 & 2.96 & -0.40 & & & \\
\hline Energy $\mathrm{T}+1$ & 6.99 & 1.55 & 11.42 & 4.66 & -0.77 & & & \\
\hline Energy $\mathrm{T}+4$ & 6.95 & 1.62 & 8.38 & 5.46 & -1.11 & & & \\
\hline Worry T-1 & 2.68 & 2.22 & 30.80 & 3.49 & 0.93 & & & \\
\hline Worry T+1 & 2.96 & 2.26 & 11.11 & 2.78 & 0.69 & & & \\
\hline Worry $\mathrm{T}+4$ & 3.10 & 2.02 & 8.08 & 2.95 & 0.59 & & & \\
\hline Sadness T-1 & 3.08 & 1.87 & 30.80 & 3.95 & 0.83 & & & \\
\hline Sadness $\mathrm{T}+1$ & 3.37 & 1.99 & 11.11 & 3.37 & 0.70 & & & \\
\hline Sadness $\mathrm{T}+4$ & 3.37 & 1.82 & 8.08 & 2.85 & 0.46 & & & \\
\hline Anger T-1 & 3.93 & 1.82 & 30.80 & 2.89 & 0.36 & & & \\
\hline Anger T+1 & 3.87 & 1.84 & 11.11 & 3.05 & 0.53 & & & \\
\hline Anger $T+4$ & 3.91 & 1.91 & 8.08 & 2.64 & 0.25 & & & \\
\hline \multicolumn{9}{|l|}{ Health related factors } \\
\hline Health impediment $\mathrm{T}+1$ & 2.90 & 2.59 & 11.42 & 2.45 & 0.57 & & & \\
\hline Improvement in health $\mathrm{T}+1$ & 5.01 & 1.56 & 11.08 & 4.91 & 0.05 & & & \\
\hline Health status $\mathrm{T}+1$ & 2.23 & 0.66 & 11.08 & 3.57 & 0.52 & & & \\
\hline \multicolumn{9}{|l|}{ Psychological factors } \\
\hline Personality: Extraversion T0 & 6.80 & 1.77 & 21.96 & 2.40 & -0.15 & .40 & .26 & .29 \\
\hline Personality: Emotional stability T0 & 6.44 & 1.70 & 21.96 & 2.91 & -0.29 & .58 & .42 & .43 \\
\hline Personality: Conscientiousness T0 & 7.42 & 1.46 & 21.96 & 2.63 & -0.25 & .32 & .20 & .26 \\
\hline Personality: Agreeableness T0 & 6.89 & 1.30 & 21.96 & 3.00 & 0.03 & .05 & .02 & .01 \\
\hline Personality: Openness T0 & 6.25 & 1.83 & 21.96 & 2.71 & -0.19 & .33 & .19 & .21 \\
\hline Number of past negative life event $\mathrm{T}-2-\mathrm{T}+4$ & 5.96 & 4.21 & 21.96 & 4.48 & 1.08 & & & \\
\hline Praying T-2 & 3.11 & 1.58 & 41.57 & 1.44 & -0.11 & & & \\
\hline \multicolumn{9}{|l|}{ Social factors } \\
\hline Relationship satisfaction T-1 & 8.05 & 1.27 & 30.80 & 3.70 & -0.52 & & & \\
\hline Social contact T-1 & 5.89 & 5.75 & 34.70 & & & & & \\
\hline \multicolumn{9}{|l|}{ Sociodemographic factors } \\
\hline Years of education T-1 & 13.24 & 3.32 & 18.12 & 2.65 & 0.18 & & & \\
\hline Having a partner $\mathrm{T}-1(\mathrm{~N}, \%)$ & 276 & 77.97 & 30.80 & & & & & \\
\hline Occupation T-1: Paid work (N, \%) & 185 & 59.87 & 27.03 & & & & & \\
\hline Financial scarcity T-1: Yes (N, \%) & 24 & 7.92 & 11.58 & & & & & \\
\hline Gender: Female T-1 (N, \%) & 204 & 57.14 & 0.00 & & & & & \\
\hline Age T-1 & 54.17 & 18.0 & 0.00 & & & & & \\
\hline
\end{tabular}

Note. $\alpha=$ Cronbach's alpha; $\lambda=$ Guttmann's lambda $6 ; \rho=$ Spearman Brown coefficient. As a reminder, the different rates of missing in the SWB indicators are due to the different sample sizes per time-point $\left(\mathrm{N}_{\mathrm{T}-1}=276, \mathrm{~N}_{\mathrm{T}+1}=324, \mathrm{~N}_{\mathrm{T}+4}=334\right)$. 
Table 2

Fit Indices of the Latent Profile Analyses at T-1, T+1, and T+4

\begin{tabular}{lcccl}
\hline No of Profiles & BIC & BLRT $(p)$ & Entropy & Profile Counts \\
\hline T-1 year before onset & & & & \\
2 & 7012.42 & $<.001$ & 0.78 & $155 / 121$ \\
3 & 6977.18 & $<.001$ & 0.80 & $130 / 109 / 37$ \\
4 & 6977.07 & $<.001$ & 0.87 & $121 / 110 / 23 / 22$ \\
$5^{\text {a }}$ & 6999.32 & $<.001$ & 0.81 & $99 / 84 / 43 / 41 / 9$ \\
$\mathrm{~T}+1$ year after onset & & & \\
3 & 8484.58 & $<.001$ & 0.81 & $174 / 123 / 28$ \\
4 & 8441.57 & $<.001$ & 0.77 & $153 / 125 / 27 / 20$ \\
5 & 8528.32 & 1.000 & 0.81 & $158 / 125 / 27 / 20 / 0$ \\
$\mathrm{~T}+4$ years after onset & & & & \\
3 & 8579.05 & $<.001$ & 0.81 & $183 / 135 / 16$ \\
4 & 8533.26 & $<.001$ & 0.78 & $158 / 140 / 21 / 15$ \\
5 & 8620.43 & 1.000 & 0.81 & $158 / 140 / 21 / 15 / 0$ \\
\hline
\end{tabular}

Note. $N_{\mathrm{T}-1}=276, N_{\mathrm{T}+1}=325, N_{\mathrm{T}+4}=334$. $\mathrm{BIC}=$ Bayesian information criterion (smaller number is preferable); BLRT = bootstrapped likelihood ratio test (nonsignificance indicates that the model with one less profile is better); Entropy (high values $>.80$ indicate a high certainty of classification); Profile Counts $=$ Final class counts and proportions for the latent classes based on their most likely latent class membership (profile counts $>5 \%$ of the overall sample size). ${ }^{a}$ Due to local maxima, this solution may not be trustworthy. ${ }^{\mathrm{b}}$ The model did not converge. The standard errors of the model parameter estimates may not be trustworthy due to a non-positive definite first-order derivative product matrix. 


\section{Figure 1}

Profiles of SWB at $T-1, T+1$, and $T+4$
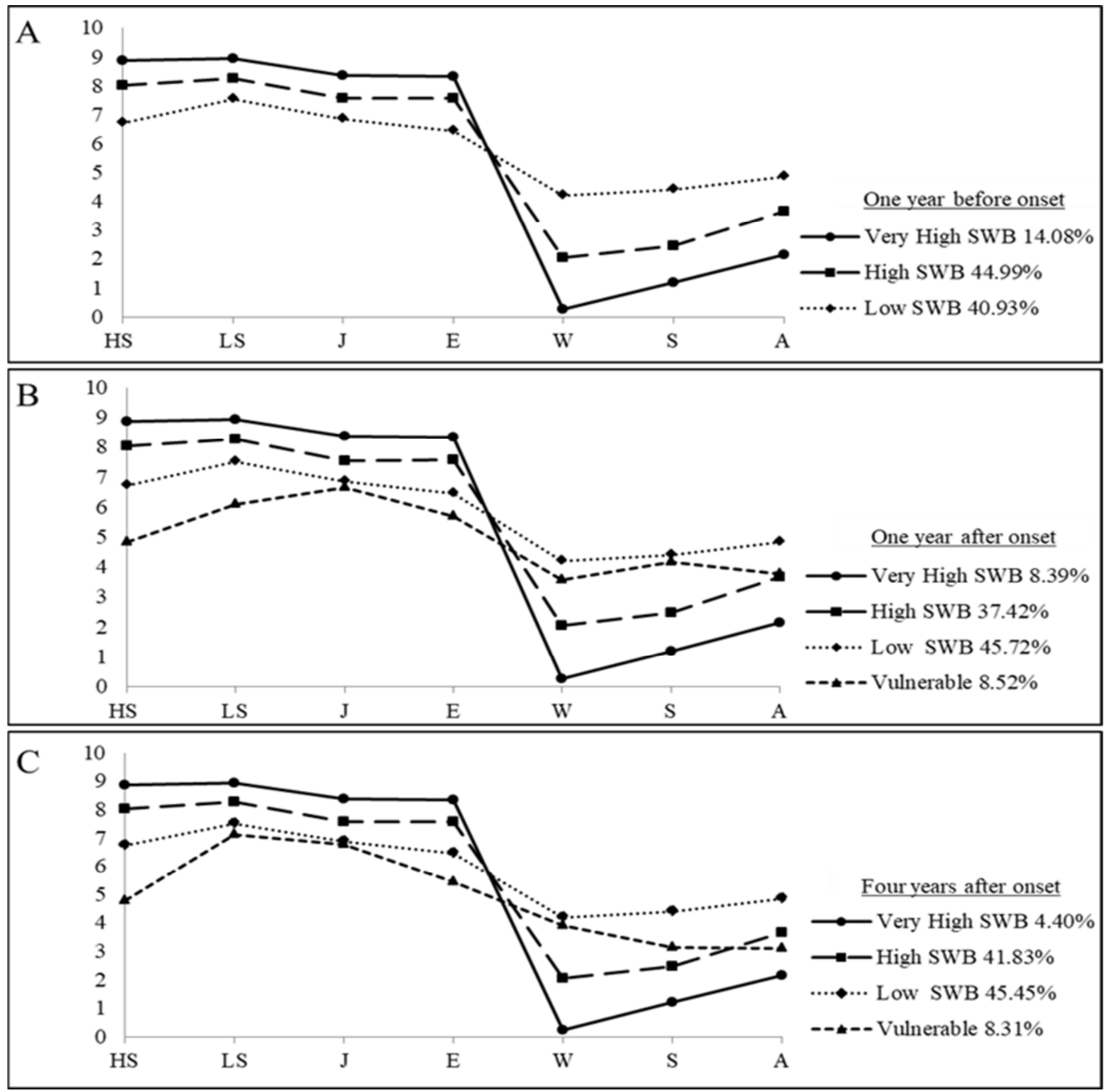

Note. A: Estimated means of the 3-profile solution one year before the onset (T-1), B: Estimated means of the 4-profile solution one year after the onset $(\mathrm{T}+1), \mathrm{C}$ : Estimated means of the 4-profile solution four years after the onset $(\mathrm{T}+4)$. SWB $=$ Subjective well-being, HS = Health satisfaction, LS = Life satisfaction, $\mathrm{E}=$ Energy, $\mathrm{J}=\mathrm{J}$ oy, $\mathrm{W}=$ Worry, $\mathrm{S}=$ Sadness, $\mathrm{A}=$ Anger. 


\section{Figure 2}

Profile transition between SWB profiles across $T-1, T+1$, and $T+4$

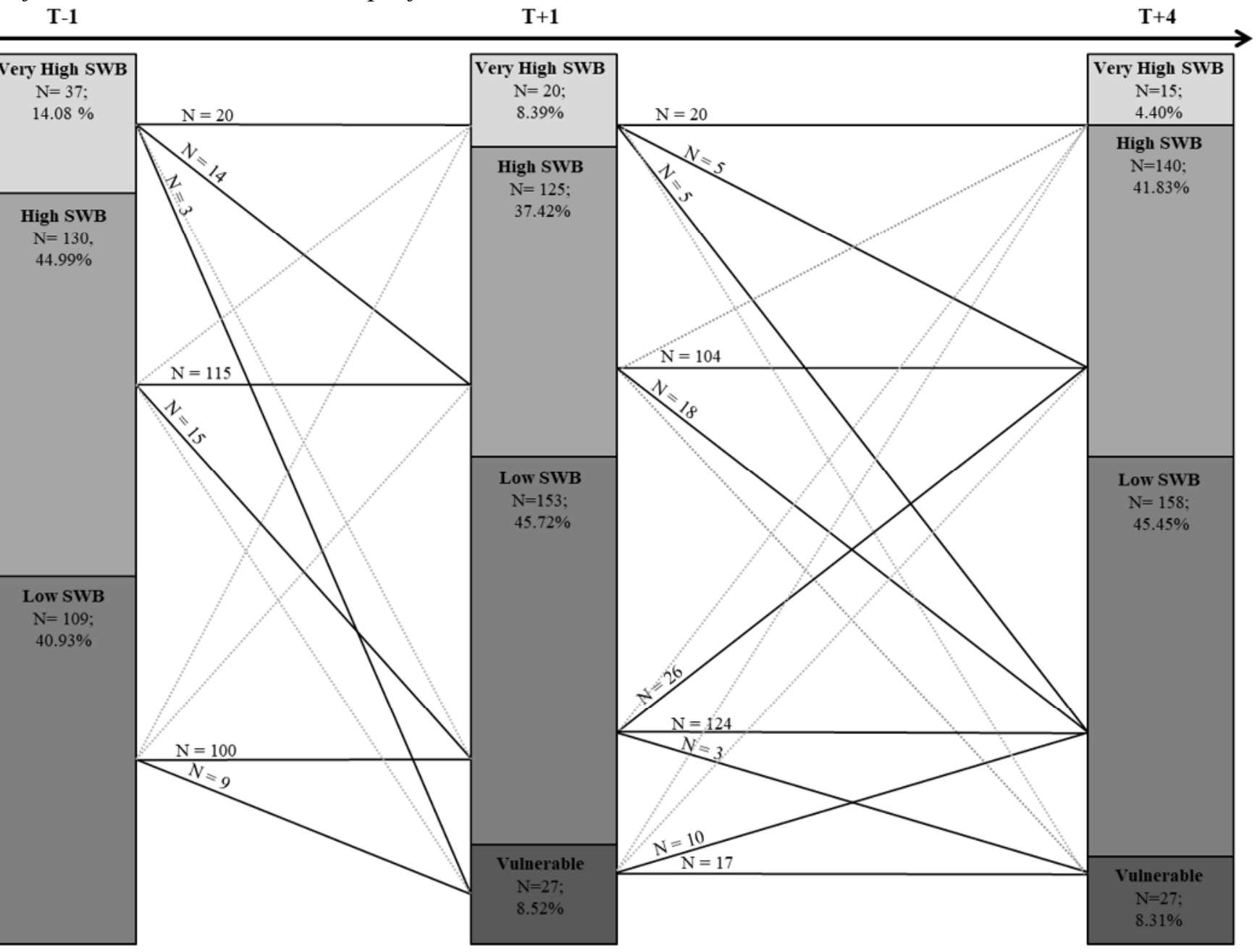

Note. Profile counts and profile transition counts are based on estimated posterior probabilities. $N_{\mathrm{T}-1}=276, N_{\mathrm{T}+1}=325, N_{\mathrm{T}+4}=334$. Transition patterns with less than two individuals are displayed with dotted lines. 


\title{
Supplementary Material
}

\section{The Longitudinal Impact of a Chronic Physical Health Condition on Subjective Well-being}

\author{
Caroline Debnar ${ }^{1,2,3}$, Valerie Carrard ${ }^{1,2,3}$, Davide Morselli ${ }^{3}$, Gisela Michel $^{2}$, Nicole Bachmann ${ }^{4}$, \\ Claudio Peter ${ }^{1,2,3}$ \\ ${ }^{1}$ Swiss Paraplegic Research (SPF), Nottwil, Switzerland \\ ${ }^{2}$ Department of Health Sciences and Medicine, University of Lucerne \\ ${ }^{3}$ Swiss Centre of Expertise in Life Course Research LIVES, University of Lausanne \\ ${ }^{4}$ University of Applied Sciences and Arts Northwestern Switzerland
}

\section{Supplementary Material}

(S1) Supplementary Figure S1. Diagram of the transition between subjective well-being profiles at one year before, one year after, and four years after physical CHC onset including predicting factors of the transition.

(S2) Supplementary Table S2. Chronic illness or long-term health problem indicators.

(S3) Mplus syntax S3. LPA Freely Estimated 3-Profile Solution (T-1).

(S4) Mplus syntax S4. LPA 4-Profile Solution $(T+1)$.

(S5) Mplus syntax S5. Latent Transition Analysis.

(S6) Mplus syntax S6. LTA including the manual three-step method.

(S7) Supplementary Table S7. Correlation of the Predictor Variables.

(S8) Supplementary Figure S8. Profiles of SWB with reversed negative emotion at T-1, T+1, and $\mathrm{T}+4$.

(S9) Supplementary Table S9. Transition Probabilities from T-1 Profiles to T+1 Profiles and from T+1 Profiles to T+4 Profiles. 


\section{Supplementary Figure S1}

Diagram of the transition between subjective well-being profiles at one year before, one year after, and four years after physical CHC onset including predicting factors of the transition

T-1 year before onset

onset

$T+1$ year after onset

$T+4$ years after onset

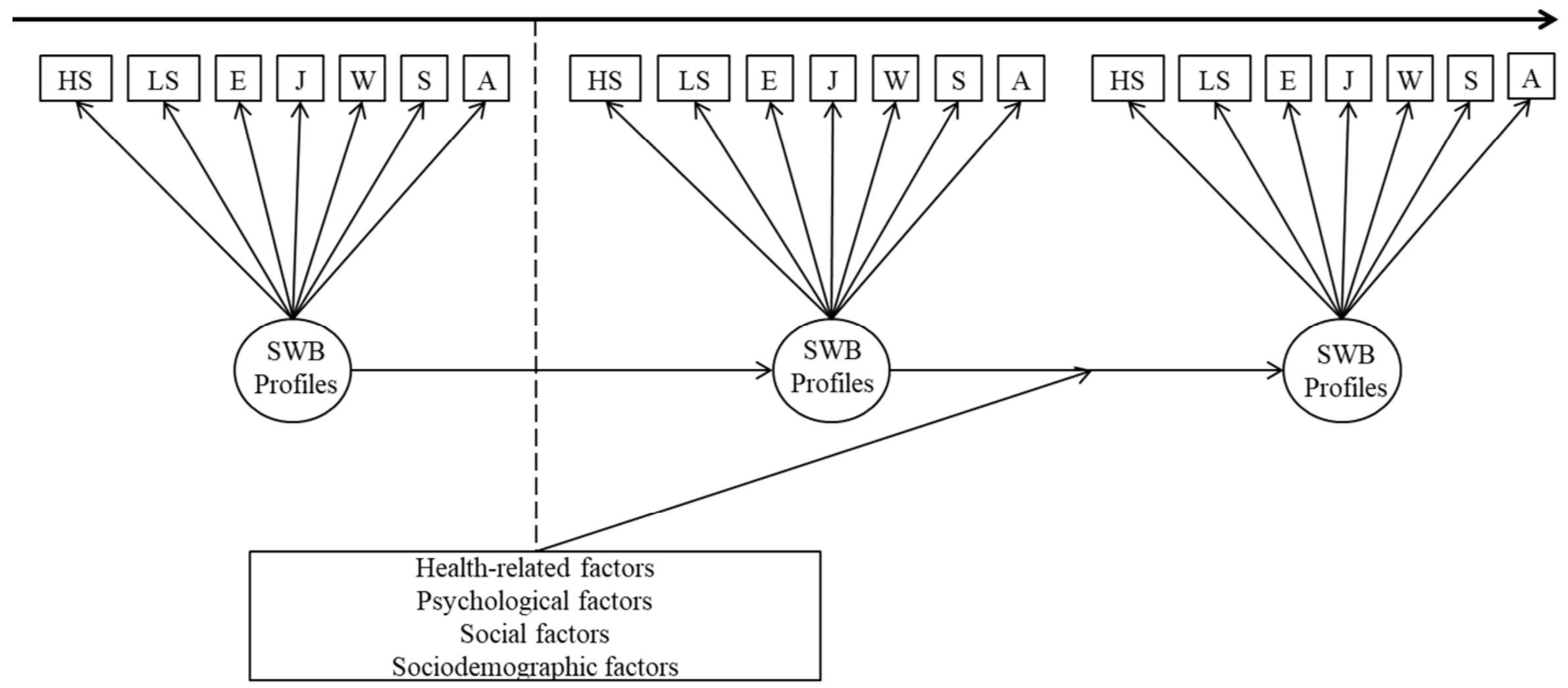

Note. $\mathrm{SWB}=$ Subjective well-being, $\mathrm{HS}=$ Health satisfaction, $\mathrm{LS}=$ Life satisfaction, $\mathrm{E}=$ Energy, $\mathrm{J}=\mathrm{J}$ oy, $\mathrm{W}=\mathrm{Worry}, \mathrm{S}=$ Sadness, $\mathrm{A}=\mathrm{Anger}$. 


\section{Supplementary Table S2}

Chronic illnes or long-term health problem indicators

\begin{tabular}{|c|c|c|c|c|}
\hline Variable & Item & Scale & Purpose & $\mathbf{N}$ \\
\hline Presence of CHC & $\begin{array}{l}\text { Do you suffer from (have) any chronic } \\
\text { (long standing) illness or condition } \\
\text { (health problem)? }\end{array}$ & $\begin{array}{l}0=\text { no } \\
1=\text { yes }\end{array}$ & $\begin{array}{l}\text { Select individuals who reported a chronic } \\
\text { health condition }\end{array}$ & $\mathrm{N}=2627$ \\
\hline $\begin{array}{l}\text { Physical or } \\
\text { mental cause }\end{array}$ & $\begin{array}{l}\text { Is it a physical or a psychological } \\
\text { problem? }\end{array}$ & $\begin{array}{l}1=\text { physical } \\
2=\text { psychological; } \\
3=\text { both } \\
4=\text { nor physical nor } \\
\text { psychological }\end{array}$ & $\begin{array}{l}\text { Exclude individuals who report a } \\
\text { psychological health condition }\end{array}$ & $\mathrm{N}=1953$ \\
\hline Main cause & $\begin{array}{l}\text { What's the main cause of this problem } \\
\text { (chronic illness or health problem)? }\end{array}$ & $\begin{array}{l}1=\text { disability since birth; } \\
2 \text { = work-related illness; } \\
3 \text { = other illness } \\
4 \text { = work related accident; } \\
5=\text { other accident; } \\
6 \text { = old age; } \\
7=\text { psychological trauma; } \\
8=\text { other }\end{array}$ & $\begin{array}{l}\text { Exclude individuals indicating a " } \\
\text { disability since birth" or "psychological" } \\
\text { main cause }\end{array}$ & $\mathrm{N}=2304$ \\
\hline Onset year & $\begin{array}{l}\text { Since when do you have this problem } \\
\text { (chronic illness or health problem)? }\end{array}$ & Numerical & $\begin{array}{l}\text { Select individuals with an onset between } \\
2009 \text { and } 2011\end{array}$ & $\mathrm{~N}=361$ \\
\hline
\end{tabular}


Mplus syntax S3 LPA Freely Estimated 3Profile Solution (T-1).

TITLE: LPA MODEL T-1

DATA: FILE = EHSWSA_LPA DATASET.DAT; !file name

VARIABLE :

NAMES $=$ ! names of variables in the data set

IDPERS L SATT1 L SATT3 L SATT6 E JOYT1 E JOYT3 E JOYT6 ENERGY1 ENERGY3 ENERGY6 DEPRT1 DEPRT3 DEPRT6 E WORYT1 E W̄ORYT3 E WORYT6 $\bar{E}$ SADT1 E SADT3 E SADT6 E ANGRT1 E_ANGRT3 E_ANGRT6 H_SATT1 H_SATT3 H_SATT $\overline{6}$;

USEVARIABLES $=$ !names of variables used to estimate the profiles

H_SATT1 L_SATT1 E_JOYT1 ENERGY1 E_WORYT1 E SADT1 E_ANGRT1;

MISSING = ALL (-999); !specify label for missing

IDVARIABLE = IDPERS; !names of variable identifying each participant

CLASSES $=\mathrm{C}(3) ;$ !specify the number of latent classes (profiles) estimated in the model

ANALYSIS :

ESTIMATOR = MLR; !maximum likelihood parameter estimates with standard

errors and a chi-square test statistic that are robust to non-normality, standard errors are computed using a sandwich estimator

PROCESSORS $=4$;

TYPE = MIXTURE; !specification for mixture modelling

STARTS $=10020$; ! to find a stable solution if the default starts are not

sufficient

STITERATIONS $=20 ;$ ! number of initial stage iterations

LRTSTARTS $=0010020$; ! to check if the results are sensitive to the number of

MODEL:

random starts

OOVERALL응 !part of the model that is common for all classes

oC\#1\% ! part of the model for class 1 that differs from the overall model

H SATTl ! the list of profile variable is included in each class to freely

L_SATT1 estimated the variance in each class

E JOYT1

ENERGY1

E WORYT1

E ${ }^{-}$SADT1

E ANGRT1;

\%C\#2\% ! part of the model for class 2 that differs from the overall model

H_SATT1

$\mathrm{L}^{-} \mathrm{SATT} 1$

E_JOYT1

EN $E R G Y 1$

E WORYT1

E SADT1

E ANGRT1;

대3ㄴ ! part of the model for class 3 that differs from the overall model

H SATT1

L_SATT1

$\mathrm{E}^{-}$JOYT1

ENERGY1

E WORYT1

E_SADT 1

PLOT :

E_ANGRT1;

TYPE = PLOT3; !request diagram

SERIES = H SATT1 L SATT1 E JOYT1 ENERGY1 E WORYT1 E SADT1 E ANGRT1(*); ! define $x^{-}$

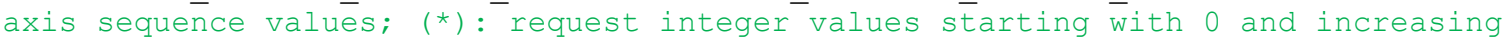
by 1

OUTPUT:

SVAL TECH11 TECH14; !SVAL: saves starting values; TECH11: requests Lo-Mendell-

Rubin likelihood ratio test of model fit; TECH14: requests a parametric

bootstrapped likelihood ratio test

SAVEDATA:

SAVE = CPROB; ! saves posterior probabilities for each latent profile

FILE = C3T1.TXT; ! set new file name 
Mplus syntax S4 LPA 4-Profile Solution (T+1).

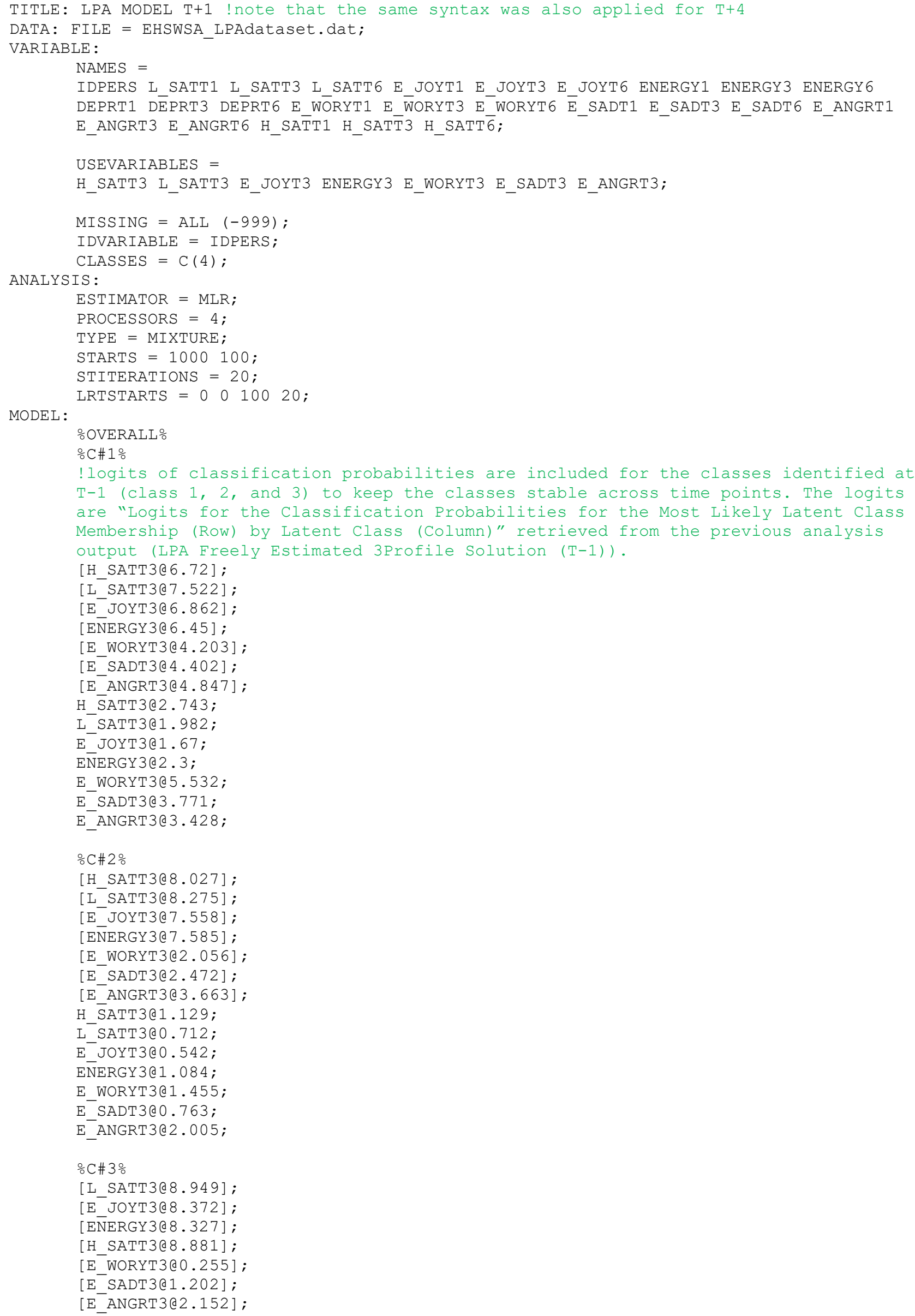




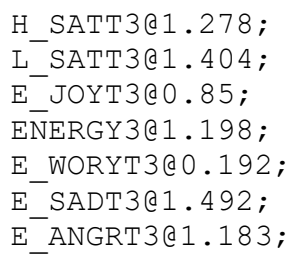

PLOT: TYPE = PLOT3;

SERIES = H SATT1 L SATT1 E JOYT1 ENERGY1 E WORYT1 E SADT1 E ANGRT1(*); OUTPUT: SVAL TECH11 TECHI4;

SAVEDATA: SAVE = CPROB LOG; !LOG: saves loglikelihood values

FILE = C3T3.TXT; 


\section{Mplus syntax S5 Latent Transition Analysis}

TITLE: LTA WITH STARTING VALUES

DATA: FILE = LPAIMPUTELIST.DAT;

TYPE = IMPUTATION; ! use the data sets generated using multiple imputation of the VARIABLE: predictor variables, for further information see Mplus user guide chapter 11

NAMES $=$

L_SATT1 L_SATT3 L_SATT6 E_JOYT1 E_JOYT3 E_JOYT6 ENERGY1 ENERGY3 ENERGY6 H_SATT1 H SATT3 H SATT6 E WORYT1 $\bar{E}$ WORYT3 ${ }^{-}$E WORYT $\overline{6}$ E SADT1 E SADT3 E SADT 6 E ANGRT 1

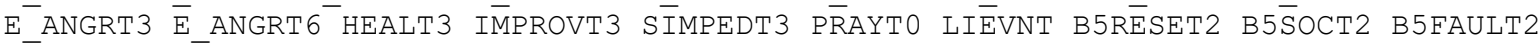

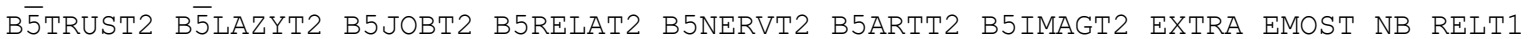
R SATT1 SEX AGE EDU YT1 INCT1 INCDUM JOBPAY PANOT1 PANOLIT1 PALIT1 ZAGE2 ZAGE TİCPROB1 T1CPROB2 TİCPROB3 T3CPROB1 T3CPROB2 T3CPROB3 T3CPROB4 T6CPROB1 T6CPROB 2 T6CPROB3 T6CPROB4 CT1 CT3 CT6 IDPERS;

USEVARIABLES = CT1 CT3 CT6; !variables indicating class/profile membership for each participant at each time point ( $\mathrm{CT} 1=\mathrm{T}-1, \mathrm{CT} 3=\mathrm{T}+1, \mathrm{CT} 6=\mathrm{T}+4)$. These memberships to class/profiles were extracted from the best fitting models identified in the preceding profile analysis

NOMINAL = CT1 CT3 CT6; ! to specify which dependent variables are treated as unordered categorical (nominal) variables in the model and its estimation MISSING = ALL $(-999) ;$ IDVARIABLE = IDPERS; CLASSES = C1 (3) C3(4) C6(4); !specify the number of latent classes (profiles) ANALYSIS : estimated in the model; e.g., Cl (3)= 3 specified classes at T-1

ESTIMATOR $=$ MLR;

ALGORITHM = INTEGRATION; ! using maximum likelihood estimator with robust standard errors with a numerical integration algorithm

PROCESSORS $=4 ;$

TYPE = MIXTURE;

MODEL = NOCOVARIANCES; !suppressing the computation of covariance to reduce computational time

MODEL :

\%OVERALL응

C3 ON C1; !request all possible transitions from $\mathrm{T}-1$ to $\mathrm{T}+1$

C6 ON C3; !request all possible transitions from $\mathrm{T}+1$ to $\mathrm{T}+4$

MODEL C1:

C1\#1\% !logits of classification probabilities are included for the classes identified at (CT1) T-1 (Class 1, 2, and 3) to keep the classes stable in the transition analysis. The logits are "Logits for the Classification Probabilities for the Most Likely Latent Class Membership (Row) by Latent Class (Column)" retrieved from the analysis output of the LPA Freely Estimated 3Profile Solution $(\mathrm{T}-1)$

$[$ CT1\#1@2.017];

$[$ CT1\#2@-6.636];

$\circ \mathrm{C} 1 \# 2 \%$

$[\mathrm{CT} 1 \# 1 \mathrm{Q}-4.023]$;

[CT1\#2@2.289];

$\circ \mathrm{C} 1 \# 3 \%$

[CT1\#1@-3.815];

$[$ CT1\#2@-2.862];

MODEL C3:

C3\#1\% !logits of classification probabilities are included for the classes identified at (CT3) T+1 (Class 1, 2, 3, and 4) to keep the classes stable in the transition analysis. The logits are "Logits for the Classification Probabilities for the Most Likely Latent Class Membership (Row) by Latent Class (Column)" retrieved from the analysis output of LPA Freely Estimated 3Profile Solution (T+1) [CT3\#1@4.221];

[CT3\#2@1.764];

[CT3\#30-1.626];

ㄷ $3 \# 2 \%$

[CT3\#1@4.049];

[CT3\#2@6.640];

[CT3\#3@3.151];

ㄷ $3 \# 3 \%$ 


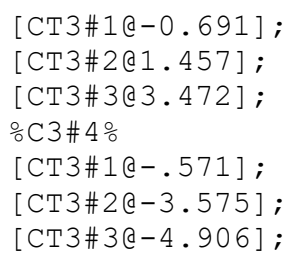

OUTPUT: SVAL TECH15; !TECH15: requests transition probabilities for each of the classes 
Mplus syntax S6 LTA including the manual three-step method (with predictor age as an example)

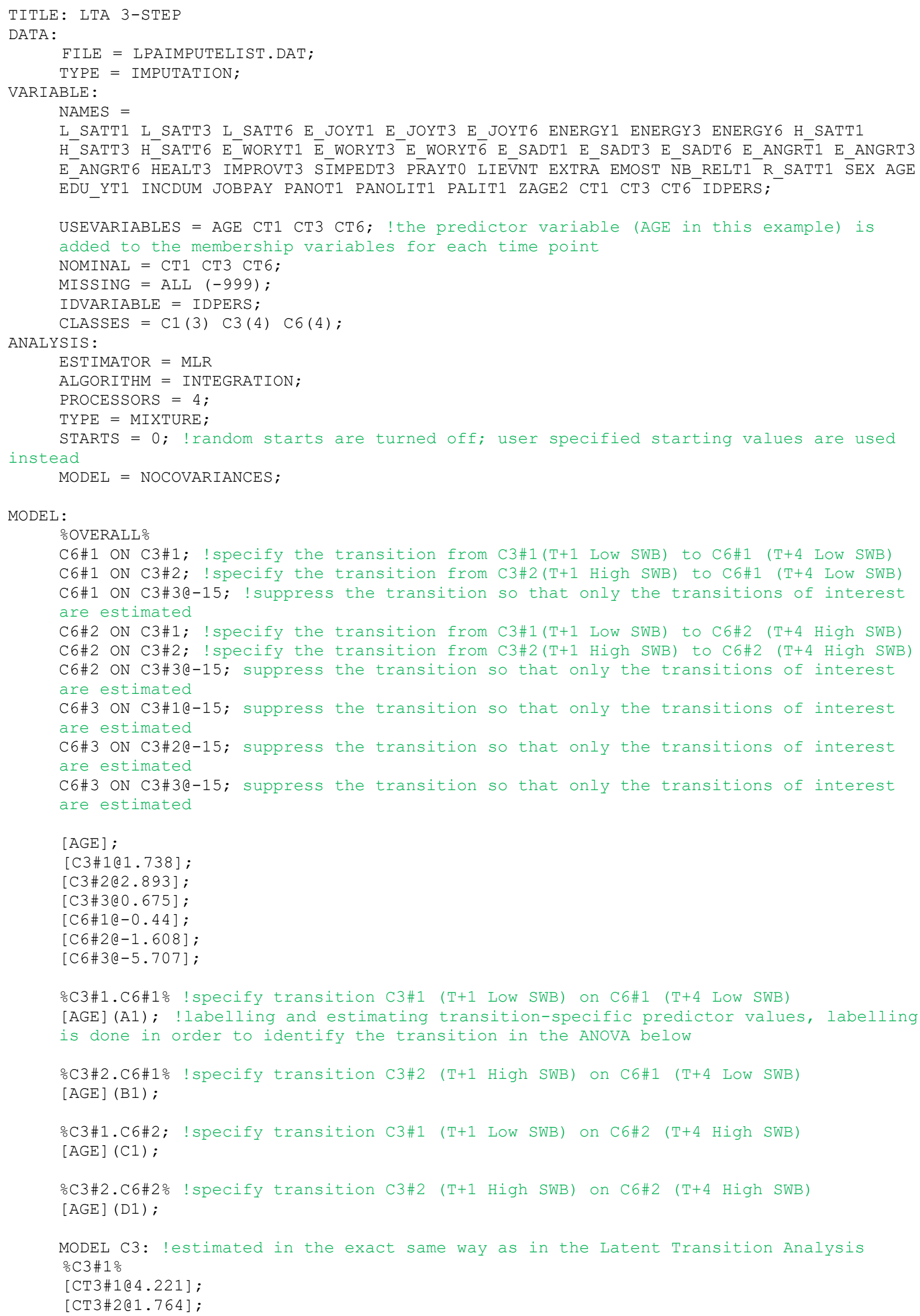




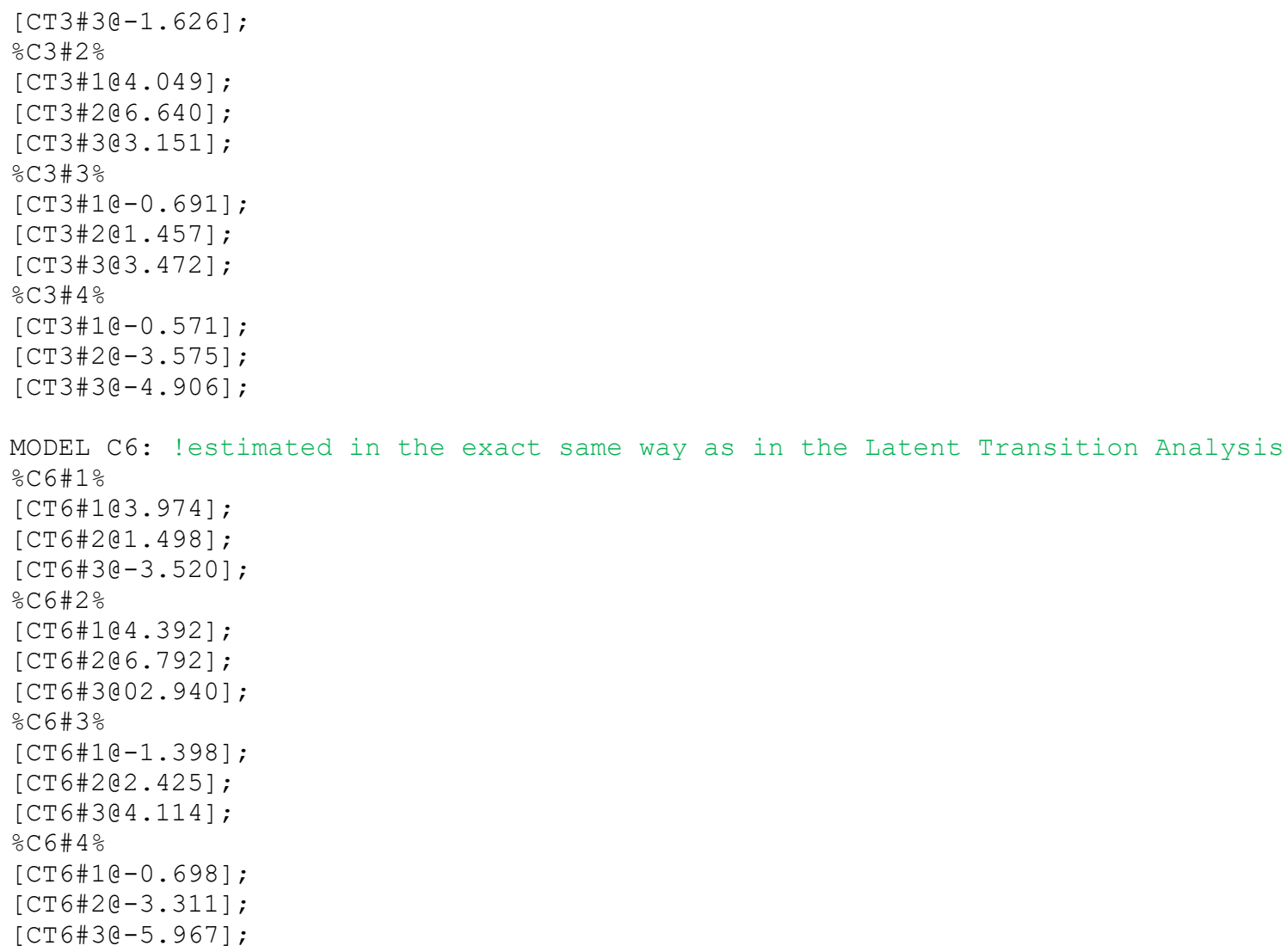

MODEL CONSTRAINT: !assigns labels and starting values to parameters that are not in the above

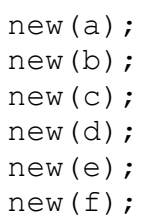

OUTPUT: SVAL; 


\section{Supplementary Table S7}

Correlation between the Predictor Variables

\begin{tabular}{|c|c|c|c|c|c|c|c|c|c|c|c|c|c|c|}
\hline & 1 & 2 & 3 & 4 & 5 & 6 & 7 & 8 & 9 & 10 & 11 & 12 & 13 & 14 \\
\hline 1 Health status & - & & & & & & & & & & & & & \\
\hline 2 Improvement in health & $-0.32 *$ & - & & & & & & & & & & & & \\
\hline 3 Health impediment & $0.49 *$ & $-0.27 *$ & - & & & & & & & & & & & \\
\hline 4 Extraversion & 0.00 & 0.05 & -0.08 & - & & & & & & & & & & \\
\hline 5 Emotional stability & -0.04 & -0.05 & -0.06 & $0.27 *$ & - & & & & & & & & & \\
\hline 6 Number of life events & $0.15^{*}$ & 0.01 & 0.72 & $0.12 *$ & 0.02 & - & & & & & & & & \\
\hline 7 Praying & 0.10 & -0.11 & 0.49 & 0.07 & -0.01 & $0.17^{*}$ & - & & & & & & & \\
\hline 8 Relationship satisfaction & $-0.20^{*}$ & 0.68 & -0.08 & $0.19 *$ & 0.10 & -0.01 & 0.02 & - & & & & & & \\
\hline 9 Social Contact & -0.05 & -0.04 & -0.05 & 0.02 & 0.07 & -0.03 & -0.05 & 0.10 & - & & & & & \\
\hline 10 Years of education & -0.06 & $-0.12 *$ & 0.00 & -0.11 & 0.08 & 0.06 & $-0.19 *$ & -0.10 & 0.06 & - & & & & \\
\hline 11 Having no partner & 0.07 & -0.09 & 0.07 & 0.01 & 0.07 & 0.12 & 0.06 & $-0.13 *$ & 0.04 & $-0.15^{*}$ & - & & & \\
\hline 12 Occupation & -0.02 & -0.11 & -0.09 & 0.01 & 0.03 & -0.09 & $-0.18 *$ & -0.01 & 0.05 & $0.36^{*}$ & -0.10 & - & & \\
\hline 13 Financial scarcity & -0.05 & 0.03 & -0.04 & 0.03 & -0.01 & $0.12 *$ & -0.03 & -0.04 & -0.01 & 0.06 & 0.10 & $-0.16^{*}$ & - & \\
\hline $14 \mathrm{Sex}$ & 0.07 & 0.06 & $0.11^{*}$ & $0.12 *$ & $-0.12 *$ & $0.15^{*}$ & $0.20 *$ & 0.02 & -0.08 & $-0.28 *$ & $0.18^{*}$ & $0.15^{*}$ & 0.05 & - \\
\hline 15 Age & $0.19 *$ & -0.09 & $0.11 *$ & -0.07 & 0.05 & $0.33 *$ & $0.24 *$ & -0.08 & -0.10 & $0.21 *$ & 0.01 & $-0.21 *$ & $0.15^{*}$ & 0.00 \\
\hline
\end{tabular}




\section{Supplementary Figure S8}

Profiles of SWB with reversed negative emotion at $T-1, T+1$, and $T+4$
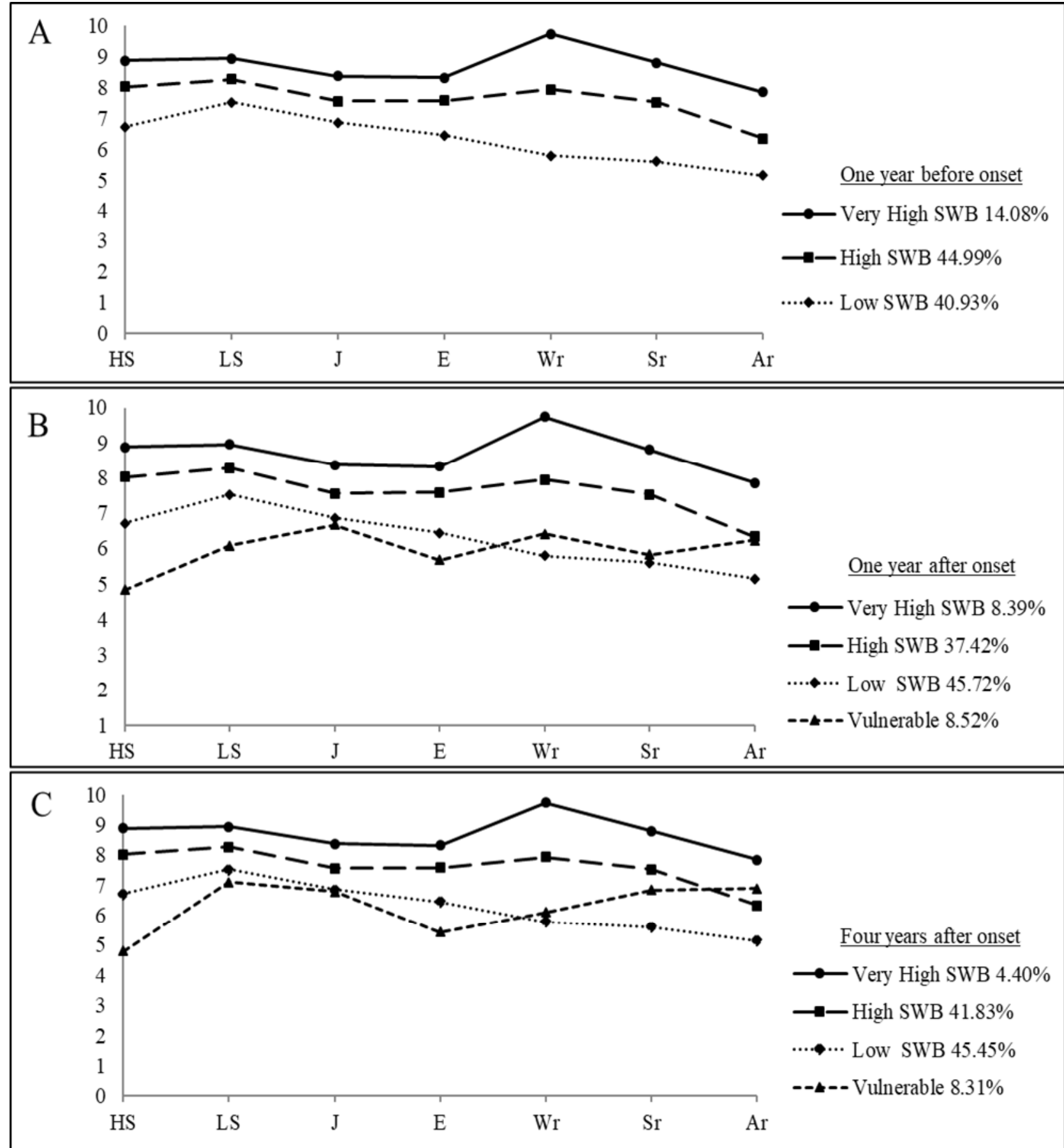

Note. A: Estimated means of the 3-profile solution one year before the onset (T-1), B: Estimated means of the 4-profile solution one year after the onset $(\mathrm{T}+1), \mathrm{C}$ : Estimated means of the 4-profile solution four years after the onset $(\mathrm{T}+4) . \mathrm{SWB}=$ Subjective well-being, $\mathrm{HS}=$ Health satisfaction, $\mathrm{LS}=$ Life satisfaction, $\mathrm{E}=$ Energy, $\mathrm{J}=\mathrm{J}$ oy, $\mathrm{Wr}=$ Worry (reversed), $\mathrm{Sr}=$ Sadness (reversed), $\mathrm{Ar}=$ Anger (reversed). 


\section{Supplementary Table S9}

Transition Probabilities from T-1 Profiles to T+1 Profiles and from T+1 Profiles to T+4 Profiles

\begin{tabular}{lcccc}
\hline Profiles & $\begin{array}{c}\mathrm{T}+1 \text { Very High SWB } \\
(n=20)\end{array}$ & $\begin{array}{c}\mathrm{T}+1 \text { High SWB } \\
(n=125)\end{array}$ & $\begin{array}{c}\mathrm{T}+1 \text { Low SWB } \\
(n=153)\end{array}$ & $\begin{array}{c}\mathrm{T}+1 \text { Vulnerable } \\
(n=27)\end{array}$ \\
\hline T-1 Very High SWB $(n=37)$ & .35 & .40 & .08 & .17 \\
T-1 High SWB $(n=130)$ & .07 & .68 & .21 & .04 \\
T-1 Low SWB $(n=109)$ & .00 & .04 & .85 & .11 \\
\hline & $\mathrm{T}+4$ Very High SWB & $\mathrm{T}+4$ High SWB & $\mathrm{T}+4$ Low SWB & $\mathrm{T}+4$ Vulnerable \\
& $(n=15)$ & $(n=140)$ & $. n=21)$ & .06 \\
\hline $\mathrm{T}+1$ Very High SWB $(n=20)$ & .41 & .33 & .80 & .04 \\
$\mathrm{~T}+1$ High SWB $(n=125)$ & .02 & .18 & .78 & .04 \\
$\mathrm{~T}+1$ Low SWB $(n=153)$ & .00 & .11 & .35 & .54 \\
$\mathrm{~T}+1$ Vulnerable $(n=27)$ & .00 & & & \\
\hline
\end{tabular}

